See Article page 585

\section{Commentary: Challenges to thoracic surgeons in the global coronavirus pandemic}

\author{
Yang Zhang, MD, and Haiquan Chen, MD, PhD
}

On January 30, 2020, the World Health Organization officially declared the outbreak of coronavirus disease 2019 (COVID-19) as a public health emergency of international concern. During this virus outbreak, many elective surgeries have been postponed. However, thoracic malignancy, especially lung cancer, has a very high incidence. For thoracic surgeons, the risk of tumor progression with delay of definitive surgery cannot be ignored.

In this article, Peng and colleagues ${ }^{1}$ investigated the clinical course of 11 patients diagnosed with COVID-19 after thoracic surgeries in January 2020. Of these patients, 7 underwent resection for lung cancer, 2 for esophageal cancer, 1 for pulmonary sclerosing pneumocytoma, and 1 for bronchiectasis. Three patients died of respiratory failure, 5 recovered and were discharged, and 3 remained hospitalized. Physiological changes after thoracic surgeries, such as leukocytosis, lymphopenia, and changes in computed tomography (CT) images, might overshadow early signs of viral pneumonia.

This article presented some important results for us to understand COVID-19 after thoracic surgeries. The COVID-19 infection rate after thoracic surgeries was high $(11 / 121 ; 9.1 \%)$. There was also a high proportion of severe illness $(36.4 \%)$ and mortality rate $(27.3 \%)$ of COVID-19 after thoracic surgeries. Therefore, during the pandemic, patients planned for thoracic surgeries should be managed with great caution.

Most importantly, unnecessary thoracic surgeries should be avoided. For patients with lung ground-glass opacity (GGO) lesions, there must be a period (4-6 months) of follow-up before surgical resection. ${ }^{2}$ During follow-up, benign GGO lesions may disappear. COVID-19, at its early stage, can also

\footnotetext{
From the Department of Thoracic Surgery, Fudan University Shanghai Cancer Center; and Institute of Thoracic Oncology, State Key Laboratory of Genetic Engineering, School of Life Sciences, and Department of Oncology, Shanghai Medical College, Fudan University, Shanghai, China.

Disclosures: Authors have nothing to disclose with regard to commercial support.

Received for publication April 6, 2020; revisions received April 6, 2020; accepted for publication April 6, 2020; available ahead of print April 10, 2020.

Address for reprints: Haiquan Chen, MD, PhD, Department of Thoracic Surgery, Fudan University Shanghai Cancer Center, 270 Dong-An Rd, Shanghai 200032,

China (E-mail: hqchen1@yahoo.com).

J Thorac Cardiovasc Surg 2020;160:593-4

$0022-5223 / \$ 36.00$

Copyright (C) 2020 by The American Association for Thoracic Surgery

https://doi.org/10.1016/j.jtcvs.2020.04.004
}

Check for updates

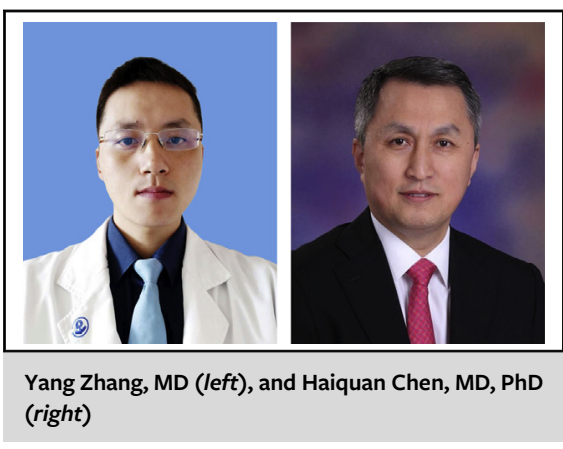

CENTRAL MESSAGE

The global pandemic of COVID-19

brings challenges to thoracic sur-

geons. It is important to avoid un-

necessary surgeries and to be alert

to the risk of COVID-19 infection

following thoracic surgeries.

present as GGO lesions on CT scans. Follow-up CT scans can help to make the differential diagnosis. Even for patients with persistent GGO lesions highly suspicious of lung cancer, they usually do not have to receive surgery immediately, as GGO-featured lung cancer is generally indolent. For patients with solid lesions suspicious of lung cancer, a short period of follow-up or needle biopsy may be considered to reduce unnecessary resections of benign lesions.

In circumstances in which surgeries cannot be delayed, there should be strict measures to prevent COVID-19 transmission. As the incubation period of COVID-19 is generally within 14 days following exposure, ${ }^{3}$ patients with an epidemiologic history should be observed for at least 2 weeks before surgery. For suspicious patients, nucleic acid testing should be performed. During anesthesia in emergency surgeries, the endobronchial blocker may be a better choice than the doublelumen bronchial tube, since the lung is not directly exposed to the air. Surgery can cause adverse effects on immune functions, which may make these patients more vulnerable to COVID-19 infection. Therefore, strict infection control practices should be followed. Since the early signs of COVID-19 may be masked by physiological changes following thoracic surgeries, thoracic surgeons should cautiously monitor their patients and also protect themselves from infection.

The global pandemic of COVID-19 brings challenges to thoracic surgeons. It is important to avoid unnecessary surgeries and to be alert to the risk of COVID-19 infection following thoracic surgeries. 


\section{References}

1. Peng S, Huang L, Zhao B, Zhou S, Braithwaite I, Zhang $\mathrm{N}$, et al. Clinical course of coronavirus disease 2019 in 11 patients after thoracic surgery and challenges in diagnosis. J Thorac Cardiovasc Surg. 2020;160: 585-92.e2.
2. Zhang Y, Jheon S, Li H, Zhang H, Xie Y, Qian B, et al. Results of low-dose computed tomography as a regular health examination among Chinese hospital employees. J Thorac Cardiovasc Surg. November 14, 2019 [Epub ahead of print].

3. Li Q, Guan X, Wu P, Wang X, Zhou L, Tong Y, et al. Early transmission dynamics in Wuhan, China, of novel coronavirus-infected pneumonia. N Engl J Med. 2020; 382:1199-207.
See Article page 585.

\section{Commentary: Echoes of war}

\author{
Gaetano Rocco, MD, FRCSEd
}

Patients with coronavirus disease 2019 (COVID-19) experience 1 of 3 possible pathways - minimal symptoms (home rest), shortness of breath (hospital admission), and need for ventilatory support (intensive care unit admission) - variably combined and yielding different outcomes. ${ }^{1}$ The article by Peng and colleagues published in this issue of the Journal ${ }^{2}$ describes the postoperative onset of COVID-19 pneumonia in patients with ascertained exposure to the contagion before surgery. Once viral pneumonia is recognized, the outcome becomes unpredictable, irrespective of the type of surgery and the wide variety of treatment regimens used to control the infection. ${ }^{2,3}$ The lesson learned from Wuhan is that we need to strike a balance between the benefit of surgery and the risks of an undue exposure to the virus for both patients and surgeons by changing the principles of managed care. ${ }^{4}$ We hear from Europe, especially from Italy, of hospitalized patients developing COVID-19 after surgery, as well as thoracic surgeons intubated after heroically providing service to these patients. In addition, fewer and fewer thoracic surgical units are operative, with the majority converted to COVID-19 step-down wards.

In New York City, the new epicenter of the disease, we have just begun ramping up the curve of the contagion. The frightening $27 \%$ mortality risk reported by Peng and colleagues should make us rethink our strategies and reshape our approach to the patient. ${ }^{2}$ The availability of

\footnotetext{
From the Thoracic Service, Department of Surgery, Memorial Sloan Kettering Cancer Center, New York, NY.

Disclosures: Author has nothing to disclose with regard to commercial support.

Received for publication March 27, 2020; revisions received March 27, 2020; accepted for publication March 30, 2020; available ahead of print April 10, 2020. Address for reprints: Gaetano Rocco, MD, FRCSEd, Thoracic Service, Department of Surgery, Memorial Sloan Kettering Cancer Center, 1275 York Ave, New York, NY 10065 (E-mail: roccog@mskcc.org).

J Thorac Cardiovasc Surg 2020;160:594-5

$0022-5223 / \$ 36.00$

Copyright (c) 2020 by The American Association for Thoracic Surgery

https://doi.org/10.1016/j.jtcvs.2020.03.130
}

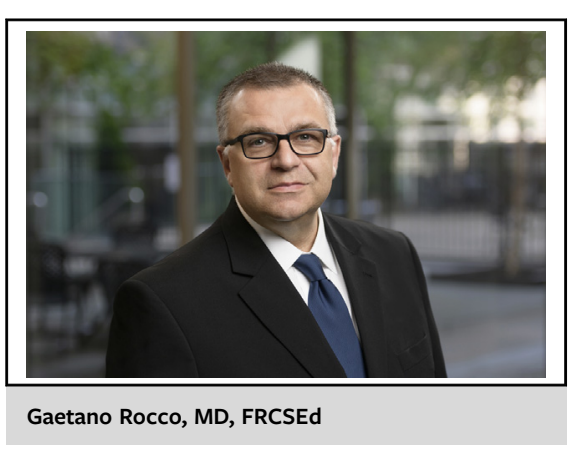

CENTRAL MESSAGE

Aggressive identification of COVID-19 surgical candidates is mandatory to avoid lethal postoperative complications and prevent exposing surgeons to the contagion.

human resources will affect the ability to continue to perform cancer surgery-those resources need to be protected..$^{5}$ The implementation of telemedicine to triage perspective new visits and provide follow-up of operated patients is rapidly becoming a necessity. ${ }^{5}$ Strict personal hygiene, social distancing, and avoidance of external visitors are effective preventative measures, especially considering the risk of spreading the contagion from asymptomatic patients. ${ }^{5}$ Accurate selection of candidates for endoscopic staging may avoid an unmeasurable exposure of clinicians and staff to a patient's exhalates. Surgical procedures that can potentially increase length of stay must be carefully selected and, if possible, postponed if we want to be ready with bed availability when the COVID-19 pandemic hits with its maximum strength. The paper from Wuhan transfers the echoes of war from the initial epicenter of the contagion. $^{2}$ For the first time after the era of tuberculosis, an airborne pathogen can potentially harm both the patient and the surgeon in the perioperative phase. In the supreme interest of both patients and surgeons, aggressive screening for COVID-19 should be used with surgical candidates, and 